\title{
FINANCIAL RISK ASSESSMENT METHODOLOGY FOR NATURAL HAZARDS
}

\author{
Rajesh P Dhakal ${ }^{1}$ and John B Mander ${ }^{1}$
}

\begin{abstract}
SUMMARY
Engineered facilities are deemed safe if they have little or no probability of incurring damage when subjected to regular actions or natural hazards. Any probability of the performance of any designed system (i.e. capacity) not being able to meet the performance required of it (i.e. demand) results in risk, which might be expressed either as a likelihood of damage or potential financial loss. Engineers are used to dealing with the former (i.e. damage), which gives a fair indication of repair/strengthening work needed to bring the system back to full functionality. Nevertheless, other non-technical stakeholders (such as owners, insurers, decision-makers) of the designed facilities cannot read too much from damage. Hence, risk, if interpreted in terms of damage only, will not be comprehended by all stakeholders. On the other hand, financial risk expressed in terms of probable dollar loss in easily understood by all. Therefore, there is an impetus on developing methodologies which correlate the system capacity and demand to financial risk. This paper builds on the existing probabilistic risk assessment methodology and extends it to estimate expected annual financial loss. The general methodology formulated in this paper is applicable to any engineered facilities and any natural hazard. To clarify the process, the proposed methodology is applied to assess overall financial risk of a highway bridge pier due to seismic hazard.
\end{abstract}

\section{INTRODUCTION}

Constructed facilities will be damaged when a natural hazard strikes. Nevertheless, the exact extent of damage is extremely difficult to predict as uncertainties will invariably exist in forecasting the likelihood of the hazard and also in estimating the facilities' damage due to a hazard of a given intensity. Therefore, a probabilistic interpretation of system safety taking into account all the uncertainties involved is a more rational approach than the conventional deterministic calculation, which gives no assurance to the users regarding the level of confidence/reliability of the predicted value. In disciplines such as Earthquake Engineering, the use of probabilistic risk assessment methodologies has been increasing over the last two decades. The application of these Earthquake Engineering innovations can be extended to other hazards.

Recently, the Pacific Earthquake Engineering Research (PEER) Center has developed an evaluation methodology for performance based earthquake engineering [Cornell et al 2002]. The mathematical foundations of the PEER methodology are limited to the probability of a specified type of performance not being met. This is based on the socalled triple integral formulation. Such a formulation is useful for engineers and structural designers, but gives little insight to owners, regulators, policy makers, insurers and investors to make better judgements and decisions. The intent of the work presented herein is to build on the concepts of the seismic-specific methodology and extend it to an all hazards framework.

Currently, the PEER triple integral total probability formulation is being brought into question by Der Kiureghian [2005]. He points out that real hazards, such as earthquakes, are discrete, rather than continuous, events and thus should be modelled as a Poisson process. Notwithstanding this, Der Kiureghian [2005] concedes that as formulated the PEER triple integral should give conservative results, and almost exact if the annual probabilities are small $(<0.01)$.

Until alternative formulations to the PEER triple integral obtain more widespread acceptance, it is considered to be a sound basis for further development. The final decision variable in the current PEER triple integral formulation can represent the probability of exceeding a performance requirement, which can be set to any level. Nevertheless, risk will be better understood by all stakeholders if expressed in monetary terms rather than in terms of technical parameters representing performance measures. In this study, the PEER triple integral is augmented to give an additional dimension - time. By aggregating losses over time, better information can be made available to the nonengineering community, particularly in terms of financial modelling. Therefore, this paper goes on to expand the PEER triple integral to a fourth integral and explains the significance of the methodology in general terms of expected annual losses. It then applies the proposed

\footnotetext{
${ }^{1}$ Department of Civil Engineering, University of Canterbury, N.Z. (Member)
} 
methodology to estimate the financial risk of a reinforced concrete bridge pier due to seismic hazards.

\section{METHODOLOGY}

Risk can generally be defined as the product of the probability of occurrence of a certain hazard with a prescribed intensity times the consequences of the asset being damaged due to that event. Expressed more formally in technical terms:

$$
R=P[I M] \times C
$$

in which $P[I M]=$ probability of occurrence of a hazard of magnitude $I M$ where $I M=$ intensity measure; and $C=$ consequences of the hazard. The latter may be in terms of damage, facility loss, financial loss, fatalities, or down-time. It is necessary to integrate such losses in a systematic way over all damage scenarios (whether minor or major) for all possible types of events (from small to large, that is the frequently occurring event to the most rare event possible).

All components of the proposed framework are based on the basic concept described by Equation 1. For convenience, the generic financial risk assessment methodology can be divided into several segments as explained below.

\subsection{Hazard-Recurrence Relationship}

Natural hazards are generally expressed by their magnitude in general terms (e.g. Richter scale for earthquakes); but engineers quantify the severity of natural hazards in terms of the intensity of one or more of its characteristic parameters (e.g. peak ground acceleration for earthquakes). The probability of occurrence of a natural hazard of given intensity depends on the intensity itself, as shown in Figure 1. As expected, the probability of a hazard of large intensity is small; and conversely, hazards of smaller scale/intensity are more likely to occur.

In the recurrence curve for most hazards, the horizontal axis (i.e. the annual probability/frequency) is commonly plotted in logarithmic scale. The horizontal axis of the hazardrecurrence curves may also be plotted in terms of the "Return period" which is the reciprocal of the annual frequency. The hazard-recurrence curve can be mathematically expressed as:

$$
I \tilde{M}=f_{1}\left(P_{a}\right)
$$

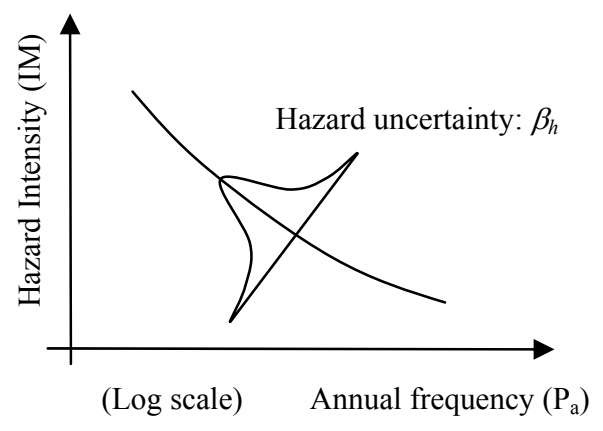

Figure 1: Hazard-recurrence relation. in which $I \tilde{M}=$ median value of intensity measure of a hazard; $P_{a}=$ annual frequency (probability); and $f_{1}\left(P_{a}\right)$ denotes a function which is established for different types of hazard based on the hazard modelling and the statistics of historical events. Note that Equation 2 gives only the median value of the hazard intensity for a given annual probability, and the uncertainty in hazard prediction can be carried forward as the lognormal coefficient of variation of the relationship, as denoted by $\beta_{h}$ in Figure 1 . The lognormal relationship is chosen for its convenience because it can be simply described by two parameters, $\tilde{x}$ and $\beta$ where $\tilde{x}=$ median and $\beta=$ lognormal coefficient of variation. For the lognormal distribution the coefficient of variation is also referred to as the dispersion factor.

\subsection{Deriving System Demand}

In a given system, a hazard of a given intensity generates a certain level of maximum/critical response. The system response may be represented by a parameter, which also serves as the demand on the system when a hazard of the prescribed intensity occurs. Obviously, the response parameter depends on the intensity of the hazard.

The system response/demand curve can also be mathematically expressed as:

$$
E \tilde{D} P=f_{2}(I M)
$$

in which $E \widetilde{D P}=$ median value of the response parameter (commonly known as the Engineering Demand Parameter) for the system; $f_{2}(I M)=$ a function of the intensity measure. To establish the function $f_{2}(I M)$, an Engineering Demand Parameter $(E D P)$ which is likely to depend on the hazard intensity needs to be identified. If an interrelationship between the hazard intensity $(I M)$ and the selected $E D P$ does not already exist, several series of analyses may be needed to predict the response/demand of the system to the hazards of various intensities and to generate $E D P$ vs. $I M$ relationships. Relationship between the median $E D P$ and $I M$ is qualitatively shown in Figure 2. Note that the uncertainty involved in analytically predicting the system response curve is represented by the lognormal coefficient of variation $\left(\beta_{a}\right)$ of the inter-relationship.

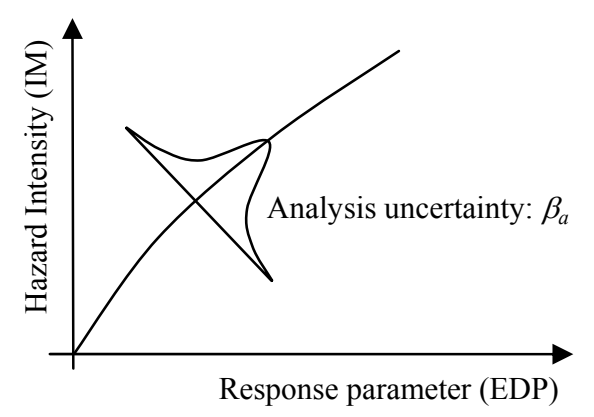

Figure 2: System response curve. 


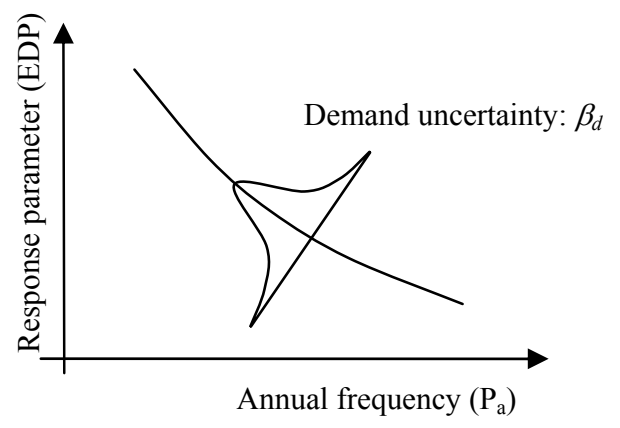

Figure 3: Engineering demand curve.

Combining the $I M$ vs. $P_{a}$ and the $I M$ vs. EDP interrelationships (i.e. Equations 2 and 3), a demand equation in generic form can be expressed as:

$$
E \widetilde{D} P=f_{3}\left(P_{a}\right)
$$

in which $f_{3}\left(P_{a}\right)=$ the function which is the product of the functions $f_{1}$ and $f_{2}$. The interrelationship in Equation 4 can also be schematically illustrated as shown in Figure 3, where the horizontal axis (i.e. the annual frequency/probability) is normally plotted in logarithmic scale.

Note that the curve in Figure 3 correlates the median value of $E D P$ with the annual frequency, and this $E D P-P_{a}$ interrelationship will have an inherent uncertainty, represented by the lognormal coefficient of variation $\left(\beta_{d}\right)$. As implied earlier, it can generally be shown that the lognormal distribution gives a good fit to the two interrelationships. Although the individual distributions may not be lognormal (they could be normal), when combined in a multiplicative fashion the composite outcome is lognormal. As the uncertainty in the $E D P$ vs. $P_{a}$ relationship is due to the hazard variability $\left(\beta_{h}\right)$ and the analysis uncertainty $\left(\beta_{a}\right)$ coming from its two components (i.e. $I M$ vs. $P_{a}$ and $E D P$ vs. $I M$ relationships respectively), the lognormal coefficient of variation of the system response/demand curve $\left(\beta_{d}\right)$ can be calculated by combining the former two according to the approach suggested by Kennedy et al [1980].

$$
\beta_{d}=\sqrt{\beta_{h}^{2}+\beta_{a}^{2}}
$$

Equation 4 represents an algebraic relationship between the median value of $E D P$ and its annual frequency. By knowing the median demand and the associated variation, the value of the demand parameter with different survival probabilities can be obtained [Martinez 2002]. The calculation needs to be dealt with numerically as in most cases a closed-form algebraic interrelationship between these parameters may not exist. For such cases, the annual frequency of the demand parameter exceeding a prescribed $e d p$, denoted as $P_{a}[E D P \geq e d p]$, can be mathematically expressed in discrete and continuous forms, respectively, as shown in the two equations to follow.

$$
\begin{gathered}
P_{a}[E D P \geq e d p]=\sum_{\text {all im }} P\left[E D P \geq e d p \mid i m_{i}\right] P_{a}\left[i m_{i}\right] \\
P_{a}[E D P \geq e d p]=\int_{0}^{1} P[E D P \geq e d p \mid i m] d P_{a}[i m]
\end{gathered}
$$

in which $P_{a}[\mathrm{im}]=$ the annual probability of the intensity measure exceeding a given value $i m$; and $P[E D P \geq e d p \mid i m]$ $=$ the probability of the demand parameter exceeding a prescribed value $e d p$ for a given hazard intensity $\mathrm{im}$. The value of $\left(P_{a}[\mathrm{im}]\right)$ is to be obtained from the hazard recurrence relationship (Figure 1) and the latter $(P[E D P \geq$ $e d p \mid i m])$ is to be obtained from response curves with different level of confidence that could be drawn in Figure 2 or could be estimated mathematically based on the median demand obtained from Equation 3 and the coefficient of variation $\beta_{a}$.

\subsection{Estimation of Damage Probability}

In order to assess the damage incurred by a hazard, damage has to be interpreted in terms of the demand parameter. It is accepted that the system resilience degrades as the incurred damage increases. Consequently, the system response parameter $(E D P)$ also qualitatively indicates the extent of damage incurred. Hence, the next step is to establish a damage model correlating the demand/response parameter $(E D P)$ and damage.

An EDP may correspond to different extent of damage within a small range and the variability may be closely represented by the lognormal distribution as qualitatively illustrated in Figure 4. The lognormal coefficient of variation of the damage model is denoted as $\beta_{d m}$ and the median value of the damage measure $(D M)$ may be expressed as a function of $E D P$ as:

$$
D \tilde{M}=f_{4}(E D P)
$$

in which $D \tilde{M}=$ median value of the damage measure; and $f_{4}(E D P)$ is a function that depends on the system resilience.

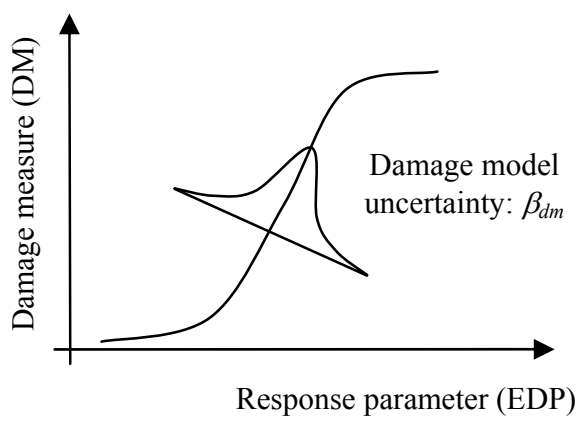

Figure 4: Damage model curve.

The interrelationship between the damage measure $(D M)$ and the response parameter $(E D P)$ may be established based on case studies, if any exists, or otherwise based on engineering judgement. Note that damage in most cases is represented in discrete terms as "limit states" rather than a continuous function as assumed above. Hence, an alternative form of Equation 8 expressing "probability of a certain limit state being exceeded for a given level of response" is used in real application instead.

The resilience equation of the system in general terms can now be derived by combining Equations 4 and 8 as

$$
D \tilde{M}=f_{5}\left(P_{a}\right)
$$

in which $f_{5}\left(P_{a}\right)$ is the function which is the product of $f_{3}$ and $f_{4}$. The graphical plot of Equation 9 is called a resilience 
curve, which is schematically shown in Figure 5. Obviously, the uncertainty of the hazard-survival relationship (i.e. $\beta_{s}$ ) is attributed to the variability in the relationships represented by Equations 4 and $8\left(\beta_{d}\right.$ and $\beta_{d m}$, respectively), and can be calculated as

$$
\beta_{s}=\sqrt{\beta_{d}^{2}+\beta_{d m}^{2}}
$$

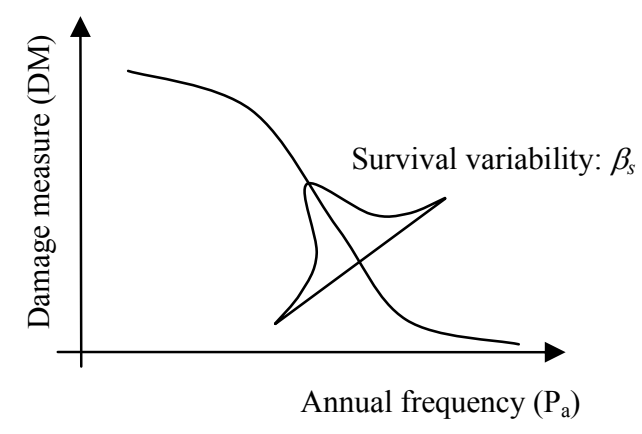

Figure 5: Hazard-survival curve.

The hazard-survival curve gives the annual frequency of a given damage measure being exceeded. As the performance requirement of the system is usually pegged with a damage measure, the hazard-survival curve also gives the annual frequency of intense hazards for which the performance of the system cannot survive (i.e. system failure). If the damage measure $(D M)$ is probabilistically plotted against the hazard intensity (i.e., $I M$ instead of $P_{a}$ in the horizontal axis in Figure 5), the resulting curves are widely known as the fragility curves.

In probabilistic terms, the annual frequency of the damage measure exceeding a prescribed limit $d m$, denoted as $P_{a}$ $[D M \geq d m]$ can be expressed mathematically in discrete and continuous forms as shown respectively in the next two equations.

$$
\begin{aligned}
& P_{a}[D M \geq d m]=\sum_{\text {all edp }} P\left[D M \geq d m \mid e d p_{i}\right] P_{a}\left[e d p_{i}\right] \\
& P_{a}[D M \geq d m]=\int_{0}^{1} P[D M \geq d m \mid e d p] d P_{a}[e d p]
\end{aligned}
$$

in which $P_{a}[e d p]=$ the annual probability of the engineering demand parameter exceeding a given value $e d p$ to be obtained from the demand curve (Figure 3); and $P$ $[D M \geq d m \mid e d p]=$ the probability of the damage measure exceeding a prescribed limit $d m$ when the demand parameter is $e d p$, which is to be obtained from the damage probability vs. demand parameter interrelationship (i.e. Figure 4) or to be calculated using the median value of $D M$ given by Equation 8 combined with the dispersion of the damage model $\beta_{d m}$.

\subsection{Interpreting Damage in terms of Financial Losses}

Damage is likely to impair the performance of the system and some repair work may be needed to restore the original (i.e. undamaged) level of functionality of the system. Hence, there certainly exists a strong correlation between the damage measure and the money required to repair the system to regain its full functionality, referred to as financial loss. For generic purposes, the financial implication of damage is specified in terms of loss ratios, defined as the ratio of financial loss (repair/replacement cost) to the replacement cost (i.e. value of the system). Obviously, the value of the loss ratio varies between zero (for no damage and normal operational performances) to 1.0 (for complete loss or ruin, necessitating total replacement). The loss ratio may be specified either as a discrete or continuous function of the damage measure, and in continuous form the relationship between the loss ratio and the damage measure can be expressed as:

$$
\widetilde{L}_{R}=f_{6}(D M)
$$

in which $\widetilde{L}_{R}=$ median value of the damage measure; and $f_{6}(D M)=$ a function that depends on the physical characteristics of the system. In graphical form, the interrelationship given by Equation 13 may be shown as in Figure 6 . The loss model is usually established based on engineering judgement, and hence has uncertainty associated with it. The loss model uncertainty can be carried forward through its lognormal coefficient of variation $\beta_{l m}$.

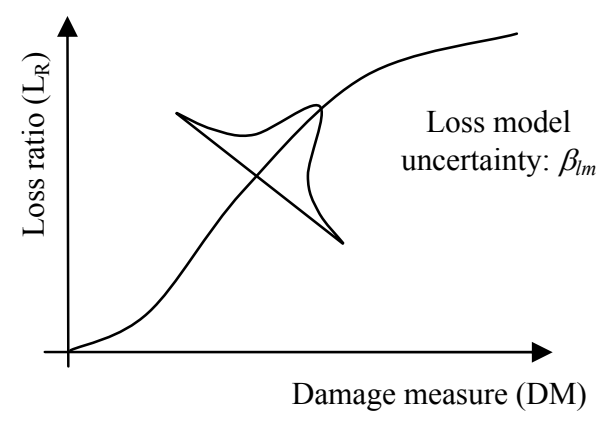

Figure 6: Loss model curve.

Combining Equations 9 and 13, the financial loss ratio can be expressed in terms of annual frequency as

$$
\widetilde{L}_{R}=f_{7}\left(P_{a}\right)
$$

in which $f_{7}\left(P_{a}\right)=$ a function which is the product of functions $f_{5}$ and $f_{6}$. Figure 7 is the graphical representation of Equation 14, which is known as the economic resilience curve (also called the financial hazard curve). This curve gives the annual probability of incurring a given financial loss. Nevertheless, the relationship between the total loss ratio and the annual frequency also has an uncertainty which can be fitted to a lognormal distribution. The lognormal coefficient of variation of the financial hazard curve (denoted as $\beta_{f}$ ) results from the hazard-survival variability and the loss model uncertainty, and can be estimated as

$$
\beta_{f}=\sqrt{\beta_{s}^{2}+\beta_{l m}^{2}}
$$




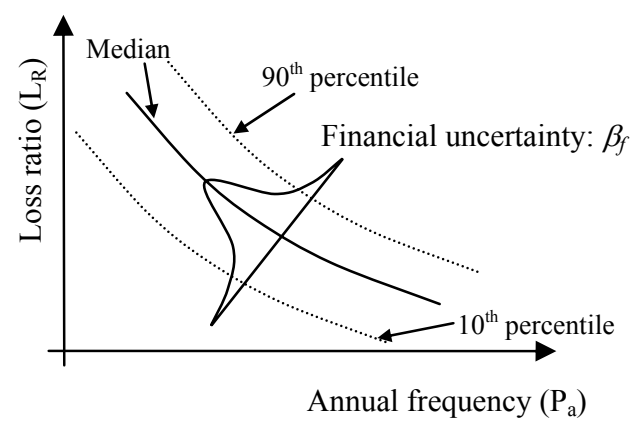

Figure 7: Financial hazard curve.

As shown in Figure 7, similar curves giving different level of confidence in the predicted financial loss can be generated from the median curve and the lognormal coefficient of variation $\beta_{f}$. In probabilistic terms, the annual frequency of the loss ratio exceeding a given value $l_{r}$, denoted as $\mathrm{P}_{\mathrm{a}}\left[L_{R} \geq l_{r}\right]$, can be expressed in discrete and continuous forms as in the following two equations.

$$
\begin{aligned}
& P_{a}\left[L_{R} \geq l_{r}\right]=\sum_{\text {all } d m_{i}} P\left[L_{R} \geq l_{r} \mid d m_{i}\right] P_{a}\left[d m_{i}\right] \\
& P_{a}\left[L_{R} \geq l_{r}\right]=\int_{0}^{1} P\left[L_{R} \geq l_{r} \mid d m\right] d P_{a}[d m]
\end{aligned}
$$

in which $P_{a}[d m]$ is the annual probability of the damage measure exceeding a given value $d m$; and $P\left[L_{R} \geq l_{r} \mid d m\right]$ is the conditional probability of the financial loss ratio exceeding a prescribed value $l_{r}$ when the damage measure is $d m$. The former (i.e. $P_{a}[d m]$ ) can be obtained from the system resilience curve (Figure 5) and the later (i.e. $P\left[L_{R} \geq\right.$ $\left.l_{r} \mid d m\right]$ ) can either be obtained from the probabilistic interrelationship between the loss ratio and the damage measure (i.e. Figure 6) or be calculated using the median value of $L_{R}$ from Equation 13 combined with the lognormal coefficient of variation of the loss model $\beta_{l m}$.

\subsection{Calculating Financial Risk}

Total financial risk can be expressed as an Expected Annual Loss $(E A L)$, and can thus be calculated by integrating the loss ratio over all possible annual frequencies of the hazard; i.e. between 0 and 1. A general equation representing this integral in deterministic and continuous form is:

$$
E A L=\int_{0}^{1} L_{R} d P_{a}
$$

in which $E A L=$ expected value of the annual financial loss. Equation 18 is graphically represented in Figure 8, which shows that the expected annual loss is, in fact, the area subtended by the financial hazard curve (loss ratio vs. annual frequency curve). Hence, integrating the area beneath the financial hazard curve (i.e. $L_{R}$ vs. $P_{a}$ graph), as shown in Figure 8, gives the expected annual loss.

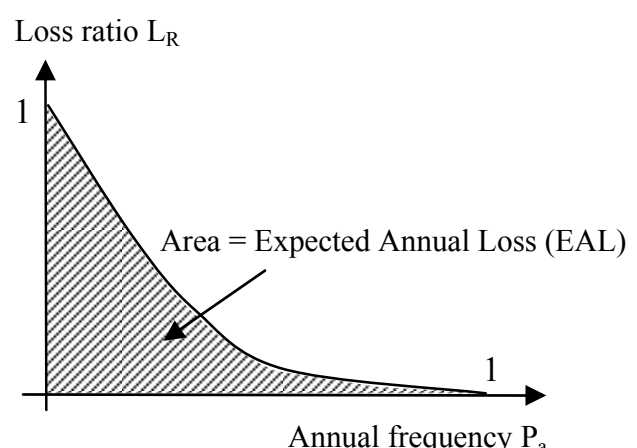

\section{Figure 8: Estimation of annual financial risk with a given confidence level.}

In discrete form, the expected annual loss $(E A L)$ can be probabilistically calculated as shown in the following equation

$$
E A L=\sum_{\text {all } l_{r, i}}\left(\frac{l_{r, i}+l_{r, i+1}}{2}\right)\left(P_{a}\left[l_{r, i}\right]-P_{a}\left[l_{r, i+1}\right]\right)
$$

in which $P_{a}\left[l_{r}\right]$ is the annual frequency of the loss ratio exceeding a given value $l_{r}$, which can be obtained from the financial hazard curve (Figure 7).

If all inter-relationships are represented as continuous functions and combined, the expected annual loss can be expressed as a quadruple integral as

$$
\begin{gathered}
E A L=\int_{0}^{1} \int_{0}^{1} \int_{0}^{1} \int_{0}^{1} L_{R} d P\left[L_{R} \mid D M\right] d P[D M \mid E D P] \\
d P[E D P \mid I M] d P_{a}[I M]
\end{gathered}
$$

in which $\mathrm{P}[\mathrm{A} \mid \mathrm{B}]$ is the conditional probability of $\mathrm{A}$ for a given value of $\mathrm{B}$; and $\mathrm{dP}[\mathrm{A} \mid \mathrm{B}]$ is the derivative of the conditional probability $\mathrm{P}[\mathrm{A} \mid \mathrm{B}]$ with respect to $\mathrm{A}$. Note that this quadruple integral is an extended version of the PEER triple integral formulation, the fourth dimension is the integration over time which was hinted, but not conducted, by Der Kiureghian [2005].

\section{APPLICATION}

The previous section has set forth the theoretical foundations for estimating the expected financial losses to a constructed facility when exposed to all possible scenarios of a particular hazard type. It has been shown that there is an interplay between facility capacity and the demand imposed by the given hazard. When these demands exceed a certain capacity threshold, damage is incurred which has a certain probability of occurrence. By expressing the damage in terms of loss ratios it is possible to compute the expected annual loss to the constructed facility. The expected annual loss is indicative of the net magnitude (without company costs or profit) of an insurance policy needed to fully cover these losses for the prescribed hazard. The expected annual financial risk can be elegantly expressed, mathematically, in terms of a quadruple integral equation.

The proposed methodology is general and can be applied to estimate expected annual loss due to any kind of natural hazard on any type of constructed facility [Dhakal and Mander 2005]. To clarify the application of the methodology, financial risk assessment of a reinforced 
concrete highway bridge due to seismic hazards is presented here.

\subsection{Seismic Risk Assessment of RC Bridges}

The generic methodology established so far is next applied in assessing the financial implications of earthquake hazard exposure to reinforced concrete bridges. For this purpose, a bridge pier designed [Tanabe 1999] using the New Zealand design code [NZS3101 1995] is adopted. The pier is $7 \mathrm{~m}$ high and is taken from a "long" multi-span highway bridge on firm soil with $40 \mathrm{~m}$ longitudinal span and $10 \mathrm{~m}$ transverse width. The weight of the super-structure reaction at each pier is assumed to be 7,000 kN. The bridge is considered to be located in a high seismic zone in New Zealand, where the design basis earthquake is characterised by a peak ground acceleration of $0.4 \mathrm{~g}$. The elevation view of the bridge and the design parameters for the pier are illustrated in Figure 9.

In order to estimate structural performance under seismic loads, Vamvatsikos and Cornell [2004] presented a procedure called "Incremental Dynamic Analysis (IDA)". This approach involves performing nonlinear dynamic analyses of a prototype structural system under a suite of ground motion records, each scaled to several intensity levels designed to force the structure all the way from elastic response to final global dynamic instability (collapse). From IDA curves, limit states can be defined. The probability of exceeding a specified limit state for a given intensity level can also be found. Furthermore, the final results of IDA are in a suitable format to be conveniently integrated with a conventional seismic hazard curve in order to calculate mean annual frequency of exceeding a certain limit-state capacity. IDA can give a clear indication of the relationship between the seismic capacity and the demand. Engineers can estimate principal response quantities, such as the maximum drift of the structure for a given intensity measure (IM) such as peak ground or spectral acceleration.

Here, IDA is performed to generate the PGA versus maximum drift relationship and the IDA results are quantitatively modelled and integrated into a probabilistic risk analysis procedure whereby the seismic intensityrecurrence relationship (the seismic demand) is viewed with respect to the damage propensity of a specific bridge structure (structural capacity). Confidence intervals and damage outcomes for given hazard intensity levels, such as the Design Basis Earthquake (DBE) or the Maximum Considered Earthquake (MCE), can then be evaluated.

The sequence of the steps of the full financial based risk assessment to be followed is explained below in detail.

\section{SEISMIC HAZARD}

\subsection{Step 1: Earthquake-Recurrence Relation}

The annual probability of occurrence of an earthquake depends on its magnitude. According to the New Zealand loading standard [NZS4203 1992], the Design Basis Earthquake (DBE) is an earthquake which has $10 \%$ probability of occurrence in 50 years; i.e. which has a return period of 475 years. Similarly, Maximum Considered Earthquake (MCE) is defined as an earthquake with $2 \%$ probability of occurrence in 50 years; i.e. approximately 2450 years return period. A return period dependent scale factor $\lambda_{T}$ such that $a_{g}^{(T=T r)}=\lambda_{T} a_{g}{ }^{(T=475 y r s)}$ (where $a_{g}{ }^{(T=T r)}$ is the PGA of an earthquake with a return period of $T_{r}$ ) is required to scale a given spectra to required return periods (or annual probabilities). Values for the return period factor have been derived by drawing a representative line through the hazard curves (PGA as a function of a return period) as illustrated in Figure 10.

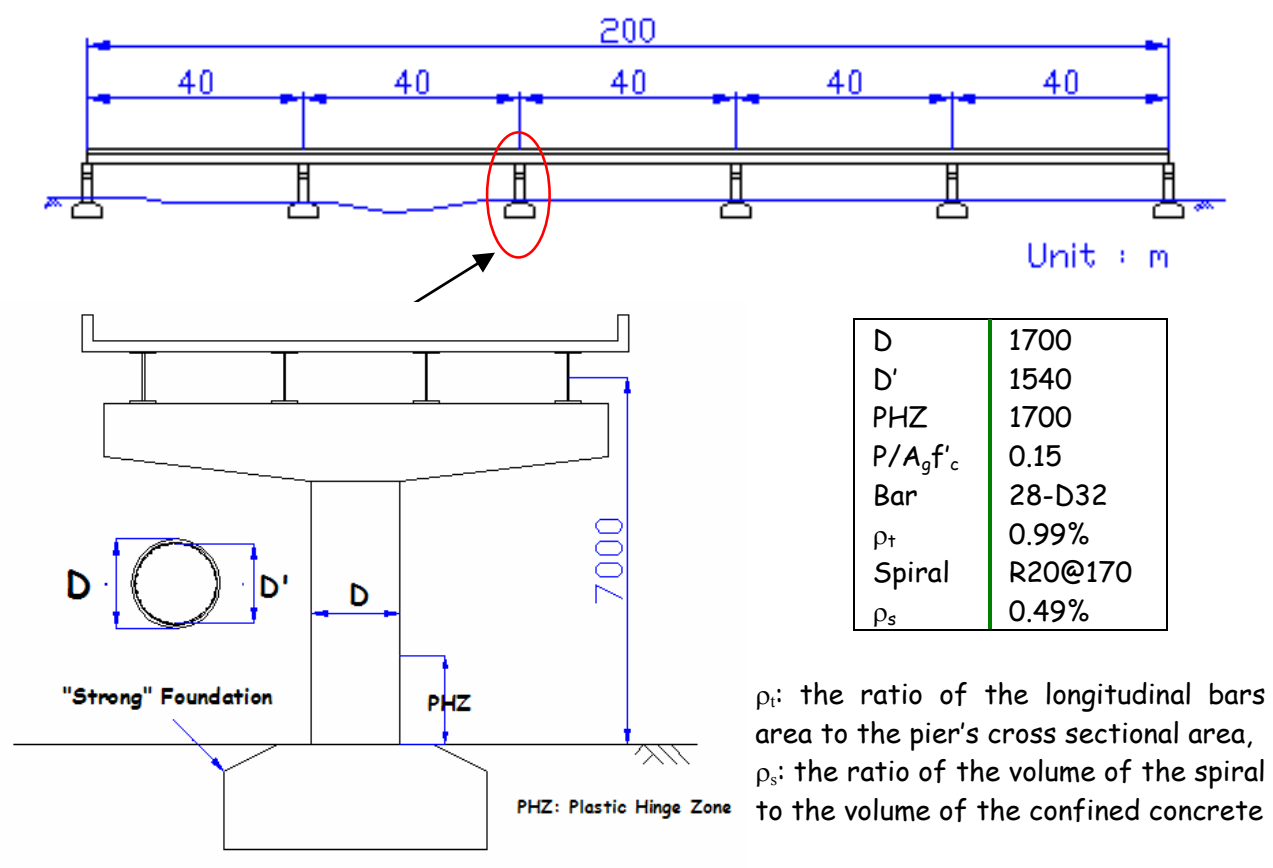

Figure 9: Design parameters of the bridge pier. 
This seismic hazard curve is described by the following equation:

$$
a_{g}{ }^{\left(T_{r}\right)}=\lambda_{T} a_{g}{ }^{(475)}=a_{g}{ }^{(475)}\left(\frac{T_{r}}{475}\right)^{q}=\frac{a_{g}{ }^{(475)}}{\left(475 p_{a}\right)^{q}}
$$

in which $a_{g}^{(T r)}=$ PGA relevant to its return period $; a_{g}^{(475)}=$ PGA with a return period of 475 years $(10 \%$ probability in 50 years); $T_{r}=$ return period; $p_{a}=$ annual probability $\left(p_{a}=1 / T_{r}\right)$; and $q=$ an exponent based on local seismicity. The value of $q=0.333$ is representative of NZ seismicity. More refined values of q may be found for regional NZ seismicity by referring to data given in Stirling et al [2002].

\section{INCREMENTAL DYNAMIC ANALYSIS (IDA)}

\subsection{Step 2: Selection of Ground Motion Records}

In order to perform IDA, a suite of ground motion records is needed. In their previous study, Vamvatsikos and Cornell [2004] used 20 ground motion records to analyse mid-rise buildings in order to provide sufficient accuracy of seismic demands. The same ground motions are adopted for this study and are presented in Table 1. These earthquakes have magnitudes in the range of 6.5-6.9 with moderate epicentral distances mostly in the range of 16 to $32 \mathrm{~km}$; all these ground motions were recorded on firm soil.

Figure 11 (a) shows the response spectra for each of the 20 earthquake ground motions scaled to the same IM, that is PGA $=0.4 \mathrm{~g}$. A significant degree of record-to-record randomness is evident with respect to the median spectral curve. Figure 11 (b) presents a plot of the lognormal coefficient of variation $\left(\beta_{D}\right)$, sometimes referred to as the record-to-record dispersion across the spectrum. For this suite of earthquakes it is evident that the dispersion stays close to $\beta=0.38$, provided that the period is less than about 1.6 seconds.
Table 1: Selection of 20 earthquake records

\begin{tabular}{|lllllll|}
\hline No & Event & Year & $\phi^{* 1}$ & $\mathbf{M}^{* 2}$ & $\mathbf{R}^{* 3}(\mathbf{k m})$ & $\mathbf{P G A}(\mathbf{g})$ \\
1 & Loma Prieta & 1989 & 90 & 6.9 & 28.2 & 0.159 \\
2 & Imperial Valley & 1979 & 135 & 6.5 & 31.7 & 0.057 \\
3 & Loma Prieta & 1989 & 255 & 6.9 & 25.8 & 0.279 \\
4 & Loma Prieta & 1989 & 270 & 6.9 & 21.4 & 0.244 \\
5 & Loma Prieta & 1989 & 285 & 6.5 & 22.3 & 0.179 \\
6 & Imperial Valley & 1979 & 85 & 6.9 & 23.6 & 0.309 \\
7 & Loma Prieta & 1989 & 270 & 6.9 & 28.8 & 0.207 \\
8 & Imperial Valley & 1979 & 140 & 6.5 & 21.9 & 0.117 \\
9 & Imperial Valley & 1979 & 90 & 6.5 & 15.1 & 0.074 \\
10 & Loma Prieta & 1989 & 0 & 6.9 & 28.8 & 0.371 \\
11 & Loma Prieta & 1989 & 360 & 6.9 & 28.8 & 0.209 \\
12 & Superstition Hills & 1987 & 90 & 6.7 & 24.4 & 0.180 \\
13 & Imperial Valley & 1979 & 282 & 6.5 & 28.7 & 0.254 \\
14 & Imperial Valley & 1979 & 230 & 6.5 & 21.9 & 0.139 \\
15 & Imperial Valley & 1979 & 180 & 6.5 & 15.1 & 0.110 \\
16 & Loma Prieta & 1989 & 0 & 6.9 & 16.9 & 0.370 \\
17 & Superstition Hills & 1987 & 360 & 6.7 & 24.4 & 0.200 \\
18 & Imperial Valley & 1979 & 45 & 6.5 & 31.7 & 0.042 \\
19 & Loma Prieta & 1989 & 165 & 6.9 & 25.8 & 0.269 \\
20 & Loma Prieta & 1989 & 90 & 6.9 & 16.9 & 0.638 \\
\hline
\end{tabular}

${ }^{1}$ Component, ${ }^{2}$ Moment Magnitudes, ${ }^{3}$ Closest Distances to Fault Rupture, and Source: PEER Strong Motion Database, http://peer.berkeley.edu/smcat/

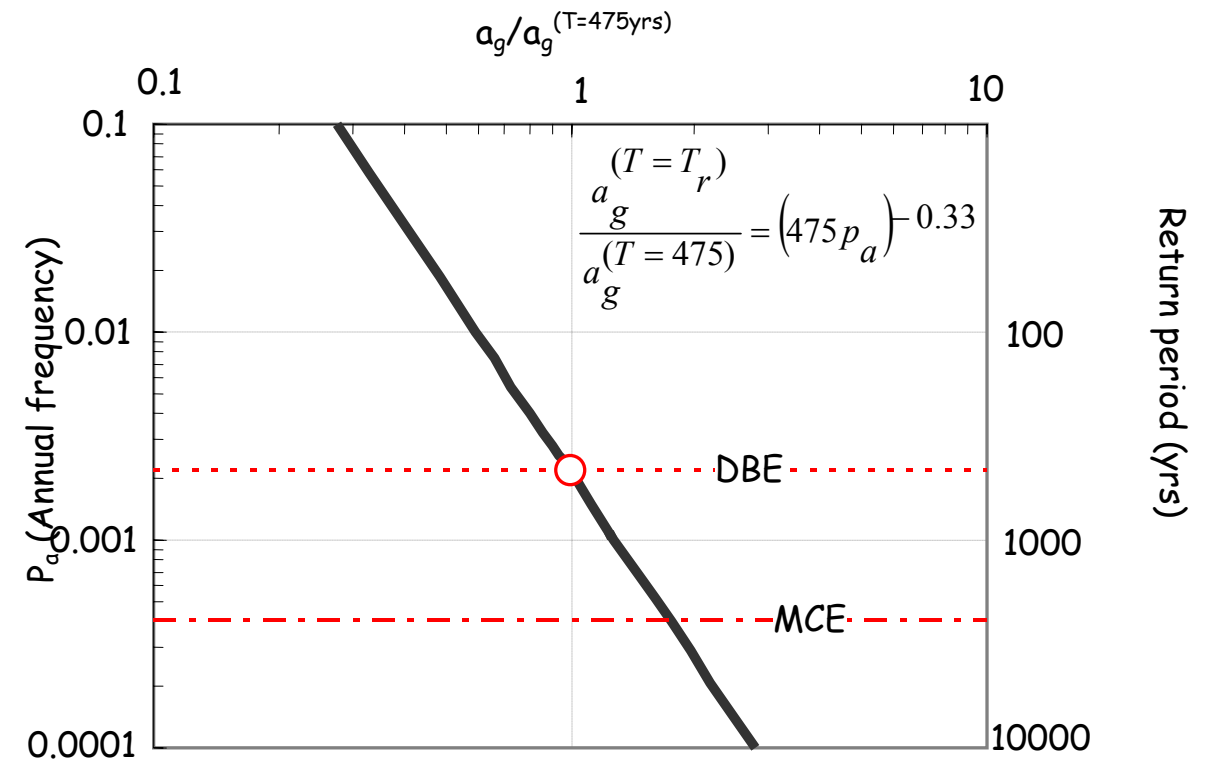

Figure 10: Hazard intensity recurrence relations. 

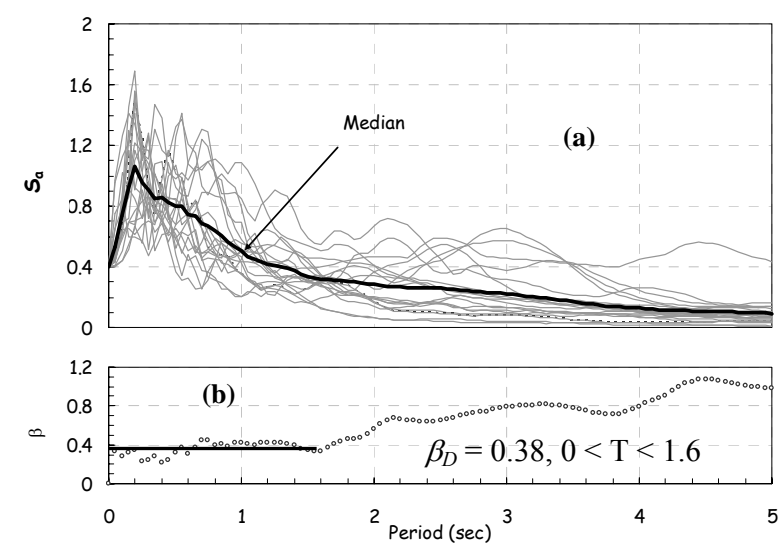

Figure 11: Ground motion records normalised to Intensity measure of $P G A=0.4 \mathrm{~g}$

Lee and Foutch [2002] compared the difference between the median responses and both the $84^{\text {th }}$ percentile and $95^{\text {th }}$ percentile values. Their results showed that the median response should be multiplied by a factor between 1.5 and 2 to estimate the $84^{\text {th }}$ percentile response and by a multiplier greater than 2.0 to generate the $95^{\text {th }}$ percentile value. This result is consistent with the findings of Martinez [2002] who also investigated the variability of results from some 20 earthquake ground motions scaled so that they each had a one-second spectral acceleration of 1g. Hence, the substantial spread of results away from the median values seen in Figure 11 is not a rare distribution.

\subsection{Step 3: Perform Incremental Dynamic Analysis}

A nonlinear computational model of the prototype bridge pier should then be developed. A check should be made that the dispersion of response demand $\left(\beta_{D}\right)$ in the neighbourhood of the natural period is reasonable. If the dispersion is excessive, then an alternative IM should be considered and this step should be repeated until the dispersion is reasonable.

Once the model and the ground motion records have been chosen, IDA is performed. To start the analysis, the earthquake record chosen are scaled from a low IM to several higher IM levels. For each increment of IM, a nonlinear dynamic time history analysis is performed. For each earthquake, analyses are repeated for higher IM's until the analysis cannot proceed further due to numerical instability; that is physical collapse occurs. For the bridge used in this study, the dynamic time history inelastic analyses were carried out using a nonlinear FE analysis program RUAUMOKO [Carr 2004]. The pier is modelled by using Takeda's model as shown in Figure 12 (a). The acceleration time history of one of the earthquakes (EQ 17) is shown in Figure 12 (b). The hysteresis (drift vs. base shear) curve and the response drift obtained from the timehistory analysis are shown in Figures 12 (c) and (d), respectively.

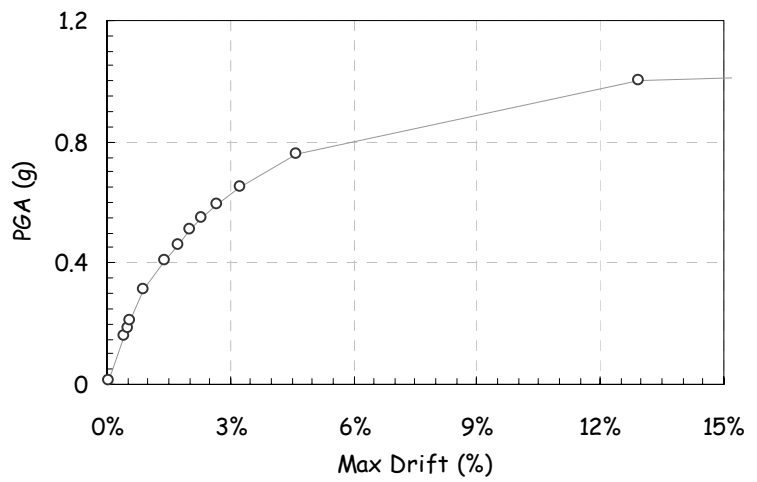

(a) IDA data points for one earthquake

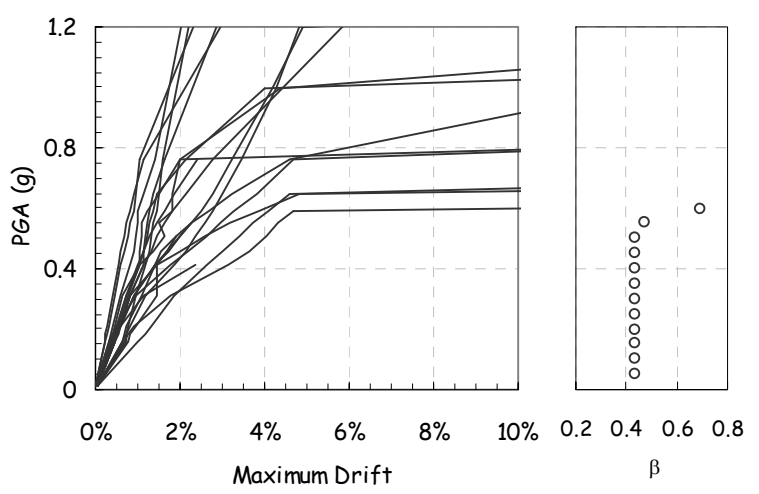

(b) IDA curves for the 20 earthquakes and the lognormal coefficient of variation $(\beta)$

\section{Figure 13: IDA curves and variation among the 20} records.

Locating the maximum drift observed in an analysis gives one point for the PGA versus maximum drift plot. As shown in Figure 13 (a), connecting such points obtained from all the analyses using one earthquake record of scaled to different intensity (PGA) gives the IDA curve for that individual earthquake. This process is then repeated for all earthquakes in the suite, as is illustrated in the left side of Figure 13 (b). It may also be of interest to analyse the variability of the response outcomes for a given level of IM. Results typically show a lognormal distribution of drift outcomes. The dispersion $(\beta)$ is also plotted on the right side of Figure 13 (b). This shows that the dispersion is mostly constant until the scaled PGA of any earthquake is not enough to collapse the pier. This partially justifies the selection of PGA as the intensity measure of seismic hazards.

\subsection{Step 4: Modelling IDA Curves and Statistical Outcomes}

In their previous study, Vamvatsikos and Cornell [2004] modelled their IDA curves by using multiple interpolation spline functions. It is considered that such an approximation is cumbersome and not particularly useful for subsequent analysis. Therefore, in this study several single functional relations were explored, and the Ramberg-Osgood (R-O) equation is adopted as the most suitable. The R-O relation is given by: 

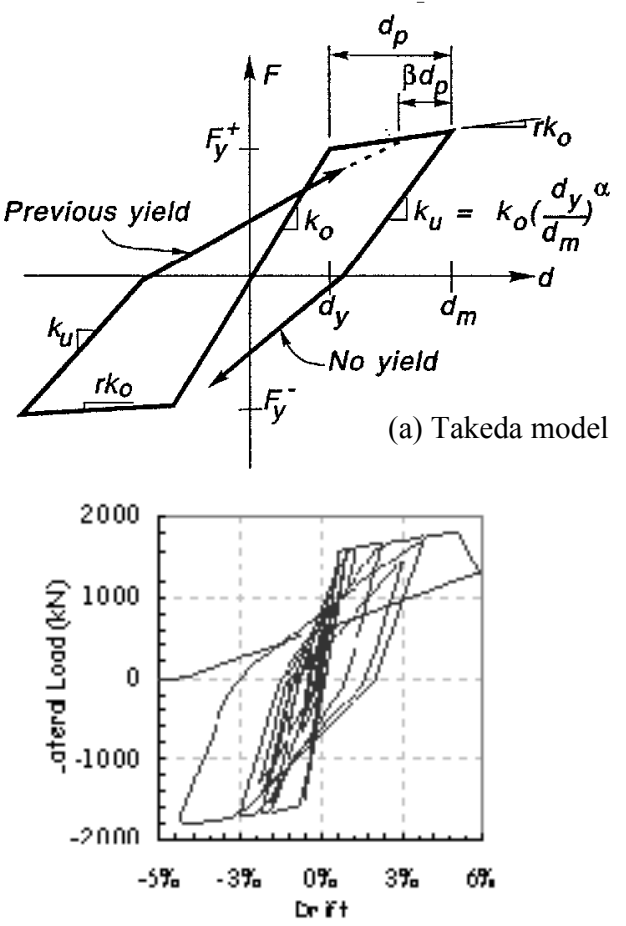

(c) Hysteresis curve

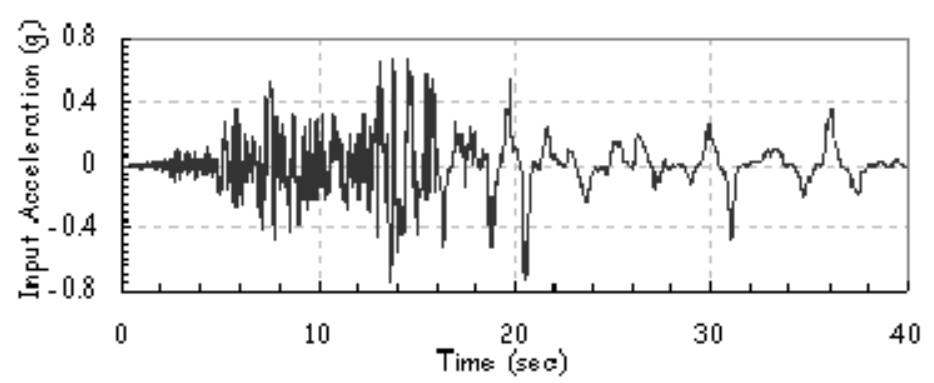

(b) Input earthquake: EQ17

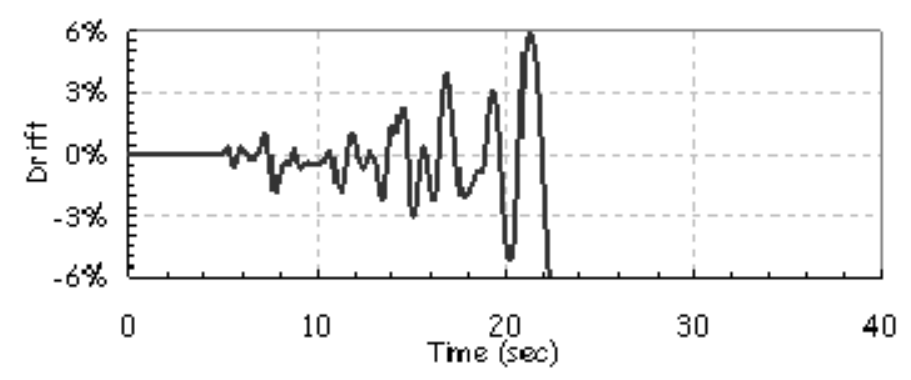

(d) Time history of drift response

Figure 12: Modelling and result of time-history dynamic.

$$
\theta=\frac{a_{g}}{K}\left(1+\left|\frac{a_{g}}{a_{c}}\right|^{r-1}\right)
$$

in which $\theta=$ drift (the engineering demand parameter); $K=$ the slope of the IDA curve in initial proportional range; $a_{c}=$ "critical" earthquake acceleration intensity that occurs at the onset of large drifts that subsequently lead to collapse; $a_{g}=$ earthquake acceleration (intensity measure); and $r=$ constant.

The R-O equation can also be written in the form

$$
\frac{\theta}{\theta_{c}}=\frac{a_{g}}{a_{c}}+\left(\frac{a_{g}}{a_{c}}\right)^{r}
$$

in which $\theta_{c}=a_{c} / K$ is a "critical" drift (critical demand parameter).

The significance of the three required control parameters $\left(a_{c}, r\right.$, and either $\theta_{c}$ or $\left.K\right)$ is examined in Figure 14 (a). As the curvature parameter $r$ increases the curve tends toward a bilinear case (when $r \rightarrow \infty$ ). If the input intensity (PGA) is greater than the "critical" value (i.e. $a_{g}>a_{c}$ ) then the response is such that $\theta>2 \theta_{c}$ and structural instability (collapse) is imminent.
Table 2: R-O modelling and parameter identification

\begin{tabular}{|c|ccc|}
\hline No & $\mathbf{a}_{\mathbf{c}}(\mathbf{g})$ & $\theta_{\mathbf{c}}(\%)$ & $\mathbf{r}$ \\
\hline 1 & 0.80 & $2.1 \%$ & 25 \\
2 & 1.80 & $4.3 \%$ & 15 \\
3 & 1.05 & $4.2 \%$ & 28 \\
4 & 1.80 & $4.0 \%$ & 18 \\
5 & 1.60 & $6.7 \%$ & 15 \\
6 & 1.20 & $4.4 \%$ & 34 \\
7 & 0.75 & $2.3 \%$ & 5 \\
8 & 0.78 & $2.0 \%$ & 36 \\
9 & 0.60 & $2.0 \%$ & 9 \\
10 & 0.70 & $4.7 \%$ & 20 \\
11 & 0.78 & $3.7 \%$ & 25 \\
12 & 0.60 & $2.9 \%$ & 15 \\
13 & 1.20 & $4.8 \%$ & 24 \\
14 & 1.40 & $2.5 \%$ & 18 \\
15 & 1.00 & $2.6 \%$ & 19 \\
16 & 3.50 & $5.6 \%$ & 18 \\
17 & 0.60 & $4.0 \%$ & 25 \\
18 & 2.10 & $3.8 \%$ & 11 \\
19 & 1.05 & $4.6 \%$ & 19 \\
20 & 3.10 & $5.0 \%$ & 35 \\
\hline $10^{\text {th }}$ & 2.90 & $5.9 \%$ & 34.8 \\
$50^{\text {th }}$ & 1.32 & $3.8 \%$ & 20.7 \\
$90^{\text {th }}$ & 0.60 & $2.5 \%$ & 12.3 \\
\hline$\beta$ & 0.61 & 0.34 & 0.41 \\
\hline
\end{tabular}




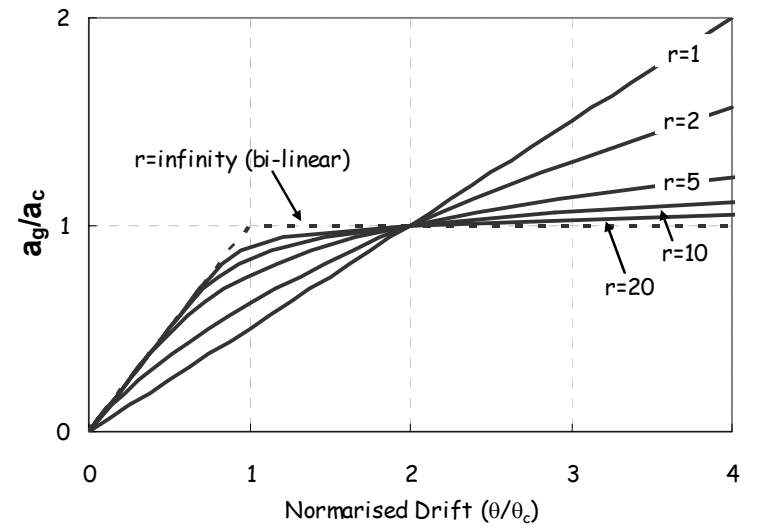

(a): Ramberg-Osgood equation for the IDA modelling

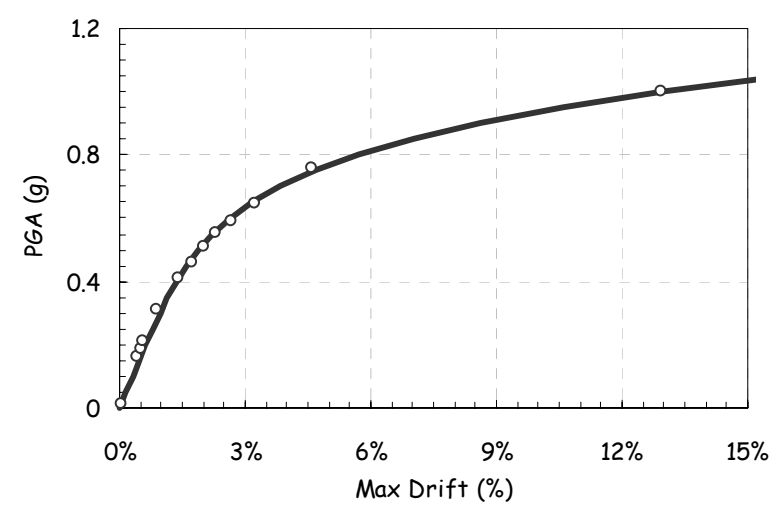

(b): An example fit of R-O model with IDA data points for one earthquake

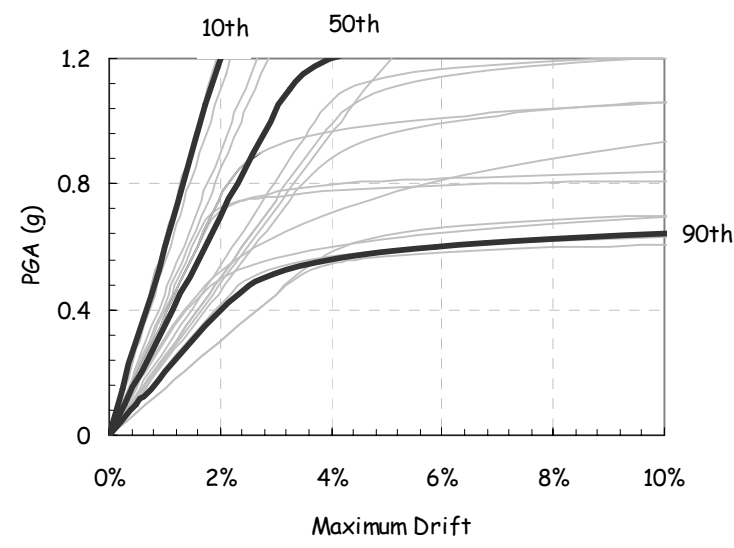

(c): Fitted IDA curves and the $10 \%, 50 \%$ and $90 \%$ fractiles

\section{Figure 14: Modelling IDA Curves and Generating Response Demand Curves.}

In Equation (22) the three control parameters $\left(a_{c}, r\right.$, and either $\theta_{c}$ or $K$ ) are estimated using nonlinear least squares analysis for each individual earthquake ground motion IDA data set. Thus obtained values of the control parameters for the different earthquakes are listed in Table 2. Figure 14 (b) illustrates the fit between the IDA data points and the fitted $\mathrm{R}-\mathrm{O}$ curve for one specific case.
Although the results for each of the control parameters are different, they can be examined collectively and a statistical analysis on the parameters can then be performed. Studies show that the parameters are lognormally distributed. Therefore by ascertaining median values of each parameter the $50^{\text {th }}$ percentile IDA response can be represented by an individual R-O median curve. Likewise by examining variability of individual IDA distributions, parameters that represent curves of other bounds of interest, such as the $10^{\text {th }}$ and $90^{\text {th }}$ percentiles may be found. Figure 14 (c) illustrates the fitted IDA curves for the suite of 20 earthquakes along with the parameter fitted R-O curves for the $10^{\text {th }}, 50^{\text {th }}$ and $90^{\text {th }}$ percentile response demand.

\section{QUANTIFICATION OF DAMAGE}

\subsection{Step 5: Assign Damage Limit States}

Once the three $\left(10^{\text {th }}, 50^{\text {th }}\right.$ and $90^{\text {th }}$ percentile) lines have been generated, it is possible to determine the expected drift for an earthquake with a certain level of intensity. Emerging international best practice for seismic design is tending to adopt a dual level intensity approach that is (i) a Design Basis Earthquake (DBE) represented by a $10 \%$ in 50 years ground motion; and (ii) a Maximum Considered Event (MCE) represented by a $2 \%$ in 50 years earthquake.

Several damage limit-states can be defined on the IDA curves developed. In their previous research, Vamvatsikos and Cornell [2004] applied building use criteria of Immediate Occupancy (IO) and Collapse Prevention (CP) limit-states to their IDA curves. In this study, the damage states defined by Mander and Basoz [1999], as listed in Table 3, are extended to the IDA curves developed for bridges. Thus defined damage states are assigned to the IDA curves in Figure 15.

Table 3: Damage states index in HAZUS [Mander and Basoz 1999]

\begin{tabular}{|c|c|c|c|c|}
\hline & $\begin{array}{l}\text { Damage } \\
\text { State }\end{array}$ & $\begin{array}{l}\text { Failure } \\
\text { Mechanism }\end{array}$ & $\begin{array}{l}\text { Repair } \\
\text { required }\end{array}$ & Outage \\
\hline DS1 & None & Pre-Yielding & None & No \\
\hline DS2 & $\begin{array}{l}\text { Minor/ } \\
\text { Slight }\end{array}$ & $\begin{array}{l}\text { Post-Yielding } \\
\text { Minor spalling }\end{array}$ & $\begin{array}{l}\text { Inspect, } \\
\text { Adjust, } \\
\text { Patch }\end{array}$ & $<3$ days \\
\hline DS3 & Moderate & $\begin{array}{l}\text { Post-Spalling } \\
\text { Bar buckling }\end{array}$ & $\begin{array}{l}\text { Repair } \\
\text { components }\end{array}$ & $<3$ weeks \\
\hline DS4 & $\begin{array}{l}\text { Major/ } \\
\text { Extensive }\end{array}$ & Bar fracture & $\begin{array}{l}\text { Rebuild } \\
\text { components }\end{array}$ & $<3$ months \\
\hline DS5 & $\begin{array}{l}\text { Complete/ } \\
\text { Collapse }\end{array}$ & Collapse & $\begin{array}{l}\text { Rebuild } \\
\text { structure }\end{array}$ & $>3$ months \\
\hline
\end{tabular}




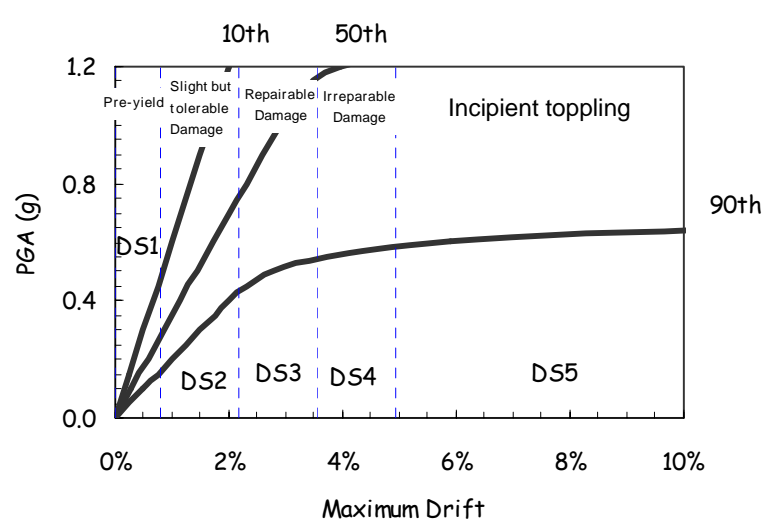

Figure 15: Assigning damage states to the IDA fractile curves.

DS1 represents elastic behaviour, it therefore concludes at the onset of damage which is best defined at the yield drift of the structure. Also, DS5 commences at the onset of collapse, and as described above this is best defined when $\theta$ $>2 \theta_{c}$ (Figure 14). The other damage stages (DS2, DS3, and DS4) are more subjective in their definitions. It is suggested that the boundary separating DS3 and DS4 be defined at a level of drift where the structure would be deemed to have suffered irreparable damage such that the structure is not likely to perform its function as evidenced by: (i) excessive permanent drift at the end of the earthquake; (ii) excessive level of damage to critical elements such as buckling of longitudinal reinforcing bars or the fracture of transverse hoops and/or longitudinal reinforcing bars. Finally, the boundary separating DS2 and DS3 should be defined as a level of damage which would cause temporary loss of function and immediate repairs are needed to restore the full functionality of the structure. This usually occurs when spalling of cover concrete is evident. At drifts below this boundary, damage (categorized as DS2) is considered to be slight and tolerable.

\subsection{Step 6: Derivation of Drift Hazard Curve}

This step could have also been before the definition of damage states; as the sequence of operations in the generic methodology suggests. The developed IDA curves can be modified more elegantly by substituting the hazardrecurrence relationship; i.e. Equation (21); into Equation (22), thereby resulting in:

$$
\begin{aligned}
& \theta=\frac{a_{g}{ }^{(T=475)}}{K\left(475 p_{a}\right)^{q}}\left(1+\left|\frac{a_{g}{ }^{(T=475)}}{a_{c}\left(475 p_{a}\right)^{q}}\right|^{r-1}\right) \\
& \text { Or, } \quad \frac{\theta}{\theta_{c}}=\frac{a_{g}{ }^{(T=475)}}{a_{c}\left(475 p_{a}\right)^{q}}+\left(\frac{a_{g}{ }^{(T=475)}}{a_{c}\left(475 p_{a}\right)^{q}}\right)^{r}
\end{aligned}
$$

Note that the parameters $a_{c}, \theta_{c}$, and $r$ depend on confidence interval. According to Martinez [2002], for an appropriate closed-form of the cumulative lognormal probability density function, the confidence interval can be estimated as

$$
C I_{\%}=\frac{100}{1+\left(\frac{x_{C I}}{\tilde{x}}\right)^{1.8 / \beta_{C / D}}}
$$

in which $\beta_{C / D}=$ composite lognormal coefficient of variation; and $\tilde{x}=$ median $(50$ percentile $)$ of the distribution of variable $x$. Using this expression the value of the parameter $x_{C I}$ for a given confidence interval CI can be estimated as

$$
x_{C I}=\tilde{x} \times\left[\frac{100}{C I}-1\right]^{0.55 \beta_{C / D}}
$$

An example of the resulting integrated risk curves is presented graphically in Figure 16 (a), which can be used to estimate the annual probability of exceeding a given damage state with a certain degree of confidence.

In the foregoing analysis it must be emphasised that the ultimate variability in response results entirely from the randomness of the input motion--that is the seismic demand. This is because the computational modelling is conducted using crisp input data. However, the structural resistance both in terms of strength and displacement capacity is also inherently variable. Moreover, the computational modelling, although it may be sophisticated, is not exact; there is a measure of uncertainty that exists between the predicted and the observed response.

To encompass the record-to-record randomness of seismic demand along with the inherent randomness of the structural capacity (aleotoric uncertainty), together with the uncertainty due to inexactness of the computational modelling (epistemic uncertainty), it is necessary to use an integrated approach as suggested by Kennedy et al [1980]. The composite value of the lognormal coefficient of variation can be expressed as

$$
\beta_{C / D}=\sqrt{{\beta_{C}{ }^{2}+{\beta_{D}}^{2}+{\beta_{U}}^{2}}^{2}}
$$

in which $\beta_{C}=$ coefficient of variation for the capacity; $\beta_{D}=$ coefficient of variation for the demand $=0.25$ assumed in this study; and $\beta_{U}=$ lognormal dispersion factor for modelling epistemic uncertainty $=0.2$ assumed in this study.

The hazard recurrence curves including the uncertainty from the computational modelling can be seen as the dotted line with $\beta_{C / D}=\sqrt{0.38^{2}+0.2^{2}+0.25^{2}}=0.5$ in Figure 16 (a). For detailed assessment, additional confidence intervals can also be plotted with the $95^{\text {th }}, 80^{\text {th }}, 70^{\text {th }}$ and $60^{\text {th }}$ percentile curves shown in Figure 16 (b). 


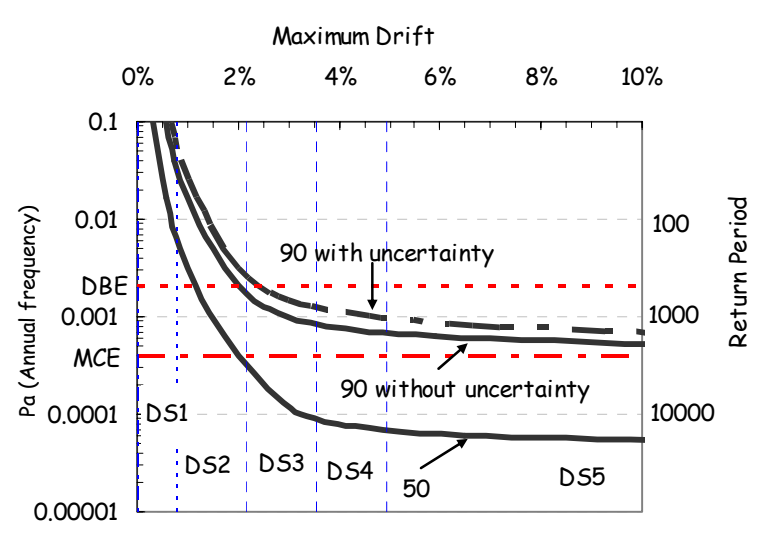

(a) Confidence intervals of response expectations based on demand randomness only and also the composite 90 percentile curve based on randomness of demand and capacity modelling uncertainty.

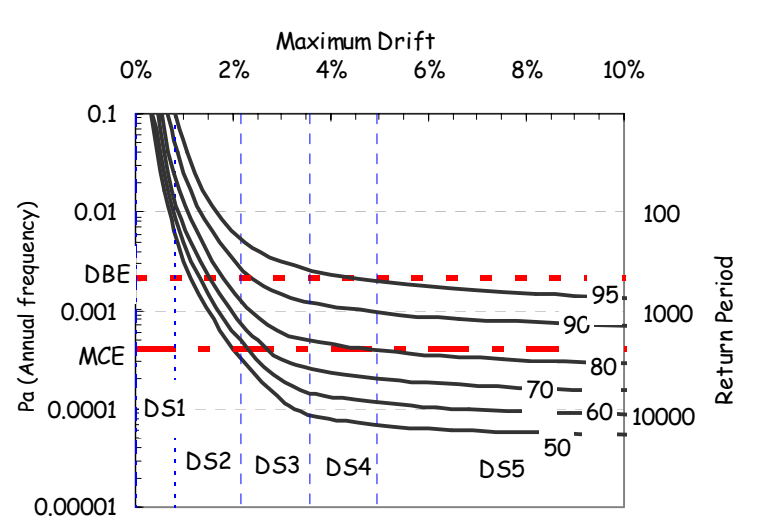

(b) Composite confidence interval curves with demand and capacity modelling uncertainty

Figure 16: Quantitative risk assessments.

\subsection{Step 7: Confidence Intervals for the Damage States}

Figure 16 is replotted in another form as shown in Figure 17. It gives the probability of the defined damage states not being exceeded when earthquakes hit the structure. Based on the annual probability or the return period of the earthquakes, Figure 17 shows the likelihood of the induced damage not crossing the limits of the five damage states.

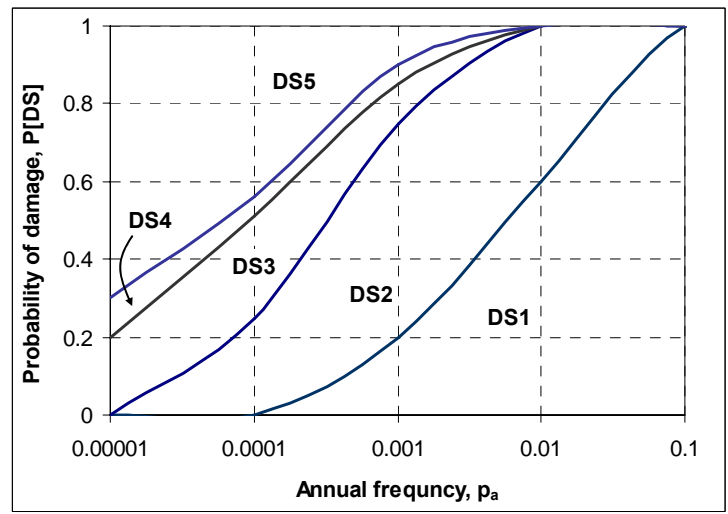

Figure 17: Quantitative Risk Assessments.
This is formed by substituting Equation (23b) into Equation (24) to give

$$
C I=\frac{100}{1+\left(\frac{a_{g}^{(T=475)}}{a_{c}\left(475 p_{a}\right)^{q}}+\left(\frac{a_{g}^{(T=475)}}{a_{c}\left(475 p_{a}\right)^{q}}\right)^{r}\right)^{1.8 / \beta_{C / D}}}
$$

The information in Figure 17 is reinterpreted in tabular form in Table 4. Table $4 \mathrm{a}$ shows the probability of the damage states not being exceeded. For example, the third row means that if an earthquake of annual frequency of 0.001 (i.e. return period of 1,000 years) strikes, the probability of DS1 not being exceeded is $20 \%$; and the corresponding probabilities for others damage states (DS2, DS3, and DS4) are $75 \%, 85 \%$, and $90 \%$, respectively.

Table 4a: Probability of exceeding different damage states

\begin{tabular}{|l|l|l|l|l|l|}
\hline $\mathbf{P}_{\mathbf{a}}$ & $\mathbf{P}[\mathrm{DS}$ 1] & $\mathbf{P}[\mathrm{DS}$ 2] & $\mathbf{P}[\mathrm{DS}$ 3] & $\mathbf{P}$ [DS4] & $\mathbf{P}$ [DS5] \\
\hline 0.1 & 1 & 1 & 1 & 1 & 1 \\
0.01 & 0.6 & 1 & 1 & 1 & 1 \\
0.001 & 0.2 & 0.75 & 0.85 & 0.9 & 1 \\
0.0001 & 0 & 0.25 & 0.51 & 0.56 & 1 \\
0.00001 & 0 & 0 & 0.2 & 0.3 & 1 \\
\hline
\end{tabular}

Table 4b: Probability of being in a given damage state

\begin{tabular}{|l|l|l|l|l|l|}
\hline $\mathbf{P}_{\mathbf{a}}$ & $\mathbf{P}[\mathrm{DS}$ 1] & $\mathbf{P}[\mathrm{DS}$ 2] & $\mathbf{P}[\mathrm{DS}$ 3] & $\mathbf{P}$ [DS4] & $\mathbf{P}$ [DS5] \\
\hline 0.1 & 1 & 0 & 0 & 0 & 0 \\
0.01 & 0.6 & 0.4 & 0 & 0 & 0 \\
0.001 & 0.2 & 0.55 & 0.1 & 0.05 & 0.1 \\
0.0001 & 0 & 0.25 & 0.26 & 0.05 & 0.44 \\
0.00001 & 0 & 0 & 0.2 & 0.1 & 0.7 \\
\hline
\end{tabular}

Table $4 \mathrm{~b}$ presents the various probabilities of being in a given damage state. For example, the third row means that when an earthquake with an annual frequency of 0.001 (approximately 1,000 years return period) strikes, there is a $20 \%$ chance that the damage state will be DS1, $55 \%$ chance that the damage will be in the range of DS2 and so on. The same information can also be reinterpreted in terms of the proportion of a large number of piers in similar bridges likely to undergo different levels of damage in a seismic event of given intensity. For example, the third row also indicates that in an earthquake with an annual frequency of 0.001 among a total of 1,000 similar piers, about 200 piers (i.e. $20 \%$ ) are likely to experience DS1, and about 550, 100, 50 and 100 piers are likely to experience DS2, DS3, DS4 and DS5, respectively 


\section{ESTIMATION OF FINANCIAL RISK}

\subsection{Step 8: Likely Financial Losses Incurred by Different Damage States}

For calculating financial risk, one needs to know what the different damage states mean in terms of financial loss. To generalize the discussions, the cost of repair or retrofit/strengthening needed to restore the functionality of the bridge is normalized with respect to the replacement cost. The normalized cost is referred to as the loss ratio hereafter. The assumed values and likely ranges of loss ratios for different damage states are shown in Table 5.

Table 5: Assumption: Loss ratios for different damage states

\begin{tabular}{|r|r|r|r|r|r|}
\hline & DS1 & DS2 & DS3 & DS4 & DS5 \\
\hline Assumed & 0 & 0.1 & 0.3 & 1 & 1 \\
Range & 0 & $0.05-0.15$ & $0.2-0.4$ & $1.0-1.2$ & 1 \\
\hline
\end{tabular}

As DS1 is the pre-yield damage state, neither damage nor repairs are expected. It follows that there are no financial losses, hence the loss ratio for DS1 is zero. "Slight but tolerable damage" under DS2 does not impair postearthquake functionality, but may require minor repairs at some stage. It is assumed herein that the loss ratio for DS2 will vary between 0.05 and 0.15 , and a value of 0.1 is adopted for further calculations. Similarly, DS3 refers to "moderate but repairable damage" such as spalling of cover concrete, wide cracks due to large plastic strain in the reinforcing bars etc. Repairs are expected to restore functionality. Accordingly, the loss ratio for DS3 may vary from 0.2 to 0.4 , and a representative value of 0.3 is adopted in the present analysis. "Irreparable damage" under DS4 generally means that although collapse has not occurred, the damage is too costly or uneconomic to repair, thus complete replacement is needed. Hence, the loss ratio for DS4 cannot be less than 1, and a value of 1 is used here. Finally, DS5 refers to "incipient damage or collapse" requiring total replacement. Obviously, the loss ratio for DS5 is 1.

\subsection{Step 9: Calculating and Integrating the Annual Financial Risk}

Next, the contribution of different damage states to the financial loss is estimated. Table 6 lists the probable loss ratios corresponding to different damage states when earthquakes with annual frequencies of $0.1,0.01,0.001$, 0.0001 , and 0.00001 strike. The values in Table 6 are the product of the probability of being in a given damage state (obtained from Table $4 \mathrm{~b}$ ) in earthquakes of different annual frequencies and the assumed loss ratio for the corresponding damage state from Table 5. This can also be represented by the following equation:

$$
P\left[L_{R} \mid D S_{i}\right]=P\left[D S_{i}\right] \times L_{R}\left[D S_{i}\right]
$$

Table 6: Conditional probability of loss ratio

\begin{tabular}{|c|c|c|c|c|c|}
\hline $\mathbf{P}_{\mathrm{a}}$ & $P\left[L_{R} \mid D S 1\right]$ & $\mid P\left[L_{R} \mid D S 2\right]$ & $P\left[L_{R} \mid D S 3\right]$ & $P\left[L_{R} \mid D S 4\right]$ & $P\left[L_{R} \mid D S 5\right]$ \\
\hline 0.1 & 0 & 0 & 0 & 0 & 0 \\
\hline 0.01 & 0 & 0.04 & 0 & 0 & 0 \\
\hline 0.001 & 0 & 0.055 & 0.03 & 0.05 & 0.1 \\
\hline 0.0001 & 0 & 0.025 & 0.078 & 0.05 & 0.44 \\
\hline 0.00001 & 0 & 0 & 0.06 & 0.1 & 0.7 \\
\hline
\end{tabular}

DS1 does not incur any financial loss as it does not need any repair. Similarly, the financial loss incurred by earthquakes of 0.1 or higher annual probability is also nil as such frequent events do not incur any damage which requires repair or replacement (DS2 or higher category).

As the probability of being in more severe damage states are multiplied by higher loss ratios (as shown in Table $5, \mathrm{~L}_{\mathrm{R}}$ is higher for DS4 and DS5 than for others), the higher damage states contribute more to the probable loss although the likelihood of the earthquake-induced damage falling into these severer categories is not high.

The total probable financial loss ratio due to earthquakes of a given probability is the sum of the corresponding values for the five damage states. Figure 18 plots the total probable loss ratio against the annual probability of the earthquakes. This curve gives information on what would be the financial loss if an earthquake of a given annual probability strikes once. As expected, the larger and rarer the event the greater the financial loss. Conversely, for frequent, but low intensity events, the single-event loss is small.

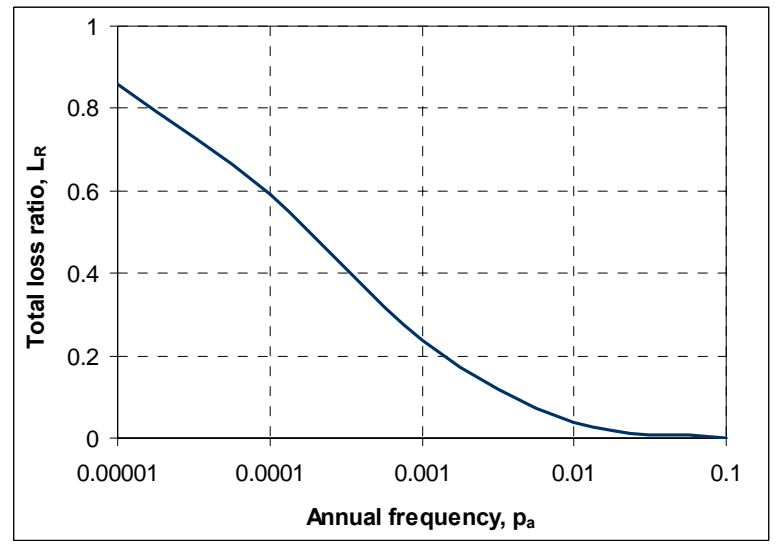

Figure 18: Probable financial loss.

Table 7: Annual expected loss calculation

\begin{tabular}{|c|c|c|c|}
\hline $\mathbf{P}_{\mathrm{a}}$ & $P\left[L_{R}\right]$ & $\begin{array}{c}\Delta \mathrm{EAL} \\
\$ 1 \text { million }\end{array}$ & $\begin{array}{c}\text { EAL } \\
\$ 1 \text { million }\end{array}$ \\
\hline & & 0 & \\
\hline \multirow[t]{2}{*}{0.1} & 0 & & \\
\hline & & $\$ 1800$ & \\
\hline \multirow[t]{2}{*}{0.01} & 0.04 & & \\
\hline & 0.235 & $\$ 1240$ & $\$ 3480$ \\
\hline 0.001 & & $\$ 370$ & \\
\hline \multirow[t]{2}{*}{0.0001} & 0.593 & & \\
\hline & & $\$ 70$ & \\
\hline 0.00001 & 0.86 & & \\
\hline
\end{tabular}


The total probable loss for earthquakes of different frequency is also shown in Table 7 (second column). In the third column of Table 7, the annual financial risk due to earthquakes of annual probability within a range is calculated. In fact, it is the area subtended by the economic hazard curve (Figure 18) between two points on the x-axis. Note that the annual probability is plotted in logarithmic scale in Figure 18, and the absolute value of the interval between any two points on the $\mathrm{x}$-axis decreases by an order of ten towards the left. Accordingly, the absolute value of the area covered is also decreasing rapidly in that direction (i.e. direction of decreasing annual probability) in spite of a higher value of the loss ratio.

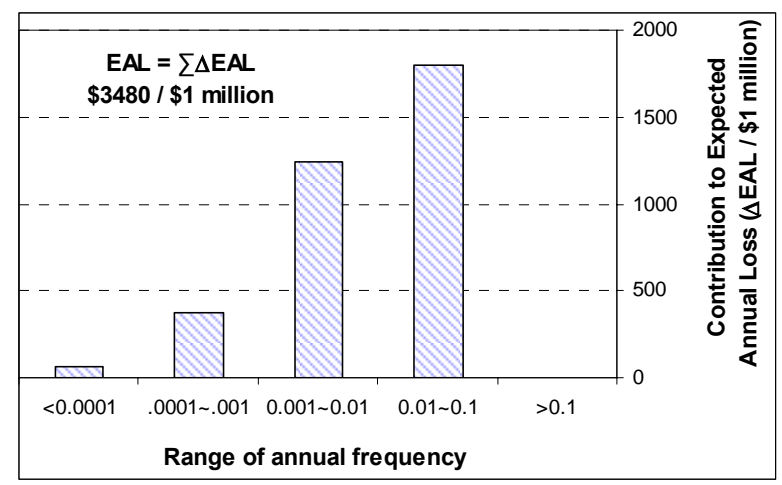

Figure 19: Annual financial risk due to earthquakes of different frequency ranges.

Thus calculated annual financial risk contribution of earthquakes in different ranges of earthquake frequencies is also depicted in Figure 19. Looking at the trend in Table 7 and Figure 19, it is reasonable to assume that the earthquakes with annual frequencies smaller than 0.00001 (return period of more than 10000 years) will pose negligible financial risk and is hence not included. It is the more frequent and smaller events that pose more financial risk, and the large earthquakes amount to very small risks due mainly to their very small annual frequency of occurrence (large return period). As is evident in Table 7 and Figure 19, the total annual financial risk (i.e. the financial risk posed by all possible earthquakes) amounts to about $0.35 \%$ of the total damages bill (i.e. replacement cost). In other words, the expected annual financial loss is $\$ 3,500$ per $\$ 1$ million of bridge value. Some $50 \%$ of this value corresponds to the risk posed by frequent but modest size earthquakes with an annual frequency in the range between 0.01 and 0.1 (i.e. return periods between 10 and 100 years).

\subsection{Limitation and Future Work}

There are several interrelationships involved in estimating the annual financial risk. The natural hazard recurrence relationship is developed based on historical data; the PGAmaximum drift relationship is derived from the results of IDA; the maximum drifts corresponding to different damage states are assumed based on experience; and the loss ratios for the different damage states are decided based on engineering judgment. There are uncertainties associated with these interrelationships which are quantitatively incorporated in the methodology in the form of coefficient of variation. Nevertheless, the uncertainties may differ from those considered in the derivation, and the change in the level of uncertainties will influence the calculated annual financial risk. Recent work by der Kiureghian [2005] has shown that the change in the extent of uncertainty will specially affect the risks posed by the frequent and modest size events. Hence, the calculated expected annual financial loss due to earthquakes with annual frequencies of more than 0.01 (return periods of less than 100 years) may differ from that described in the foregoing analysis.

The definition of loss ratios for different damage states and the values assigned to them are also somewhat subjective. The values of the loss ratios are expected to be in the range shown in Table 5, but within this range the loss ratios may have any value. A sensitivity analysis is conducted here to investigate the effect of the loss ratios assumed for DS2, DS3 and DS4. As the definitions of DS1 and DS5 make it almost certain than the corresponding loss ratios are 0 and 1 , they are not included in the sensitivity study.

Table 8 presents the results of the sensitivity analysis where the financial loss per $\$ 1$ million of asset value is listed for different assumed loss ratios. It is evident that the annual financial risk does not depend much on the loss ratios assigned to DS3 and DS4, but is particularly sensitive to the loss ratio for DS2. This indicates that the damages inflicted by more frequent but less severe events contribute the most to the overall financial risk.

Table 8: Effect of loss ratios on the annual financial risk

\begin{tabular}{|cc|cc|cc|}
\hline \multicolumn{2}{|c|}{ Sensitivity of annual financial risk $\left(\mathrm{FR}_{\mathrm{A}}\right)$ w. r. to the loss } \\
ratios of \\
\hline \multicolumn{2}{|c|}{ DS2 } & \multicolumn{2}{|c|}{ DS3 } & \multicolumn{2}{c|}{ DS4 } \\
$\mathrm{L}_{\mathrm{R}}\left(\mathrm{DS}_{2}\right)$ & Loss / $\$ 1 \mathrm{M}$ & $\mathrm{L}_{\mathrm{R}}\left(\mathrm{DS}_{3}\right)$ & $\mathrm{Loss} / \$ 1 \mathrm{M}$ & $\mathrm{L}_{\mathrm{R}}\left(\mathrm{DS}_{4}\right)$ & Loss / $\$ 1 \mathrm{M}$ \\
0.05 & $\$ 2340$ & 0.2 & $\$ 3410$ & 0.8 & $\$ 3420$ \\
0.10 & $\$ 3480$ & 0.3 & $\$ 3480$ & 1.0 & $\$ 3480$ \\
0.15 & $\$ 4610$ & 0.4 & $\$ 3540$ & 1.2 & $\$ 3530$ \\
\hline
\end{tabular}

From an insurance point-of-view, the risk of these smaller and more frequent events should be carried by the owner. This can be achieved by setting an appropriate deductible to the policy and thus keeping the remainder of the insured risk affordable for the owner.

The definition of damage states and the drift ratios corresponding to the different damage states are also subjective, particularly the boundaries between DS2 and DS3, and DS3 and DS4. The damage states are assumed as discrete functions of drift although ideally damage limits should be expressed in a probabilistic or fuzzy manner. Even when the discrete function is accepted, a small change in the drift ratios corresponding to the boundaries of different damage states will indicate somewhat different financial losses. Clearly, this should be the subject of future work. 


\section{CONCLUSIONS}

A methodology for estimating the overall financial risk to a constructed facility when exposed to a particular hazard has been established, which can be expressed mathematically in terms of a quadruple integral equation. Based on the application of the proposed methodology to bridge structures presented herein, the following conclusions can be drawn:

1. Inelastic dynamic analysis (IDA) is an elegant method of assessing seismic response in terms of a given engineering demand parameter (EDP) such as column drift to the applied seismic ground motion expressed in terms of an intensity measure (IM) which for this study was the peak ground acceleration (PGA) of the earthquake motion. IDA is a way of identifying performance through to the IM that leads to true failure via toppling.

2. Results of IDA runs for several different earthquakes can be used to assess the record-to-record randomness of response. For the medium-field ground motion suite adopted in this study, the lognormal coefficient of variation for this randomness was found to be in the order of $\beta=0.4$.

3. When combined with the sources of aleotoric and epistemic uncertainty a combined lognormal variation of response with respect to overall median performance can be taken as $\beta_{C / D}=0.5$.

4. Results from the IDA study can be used to assess the overall financial risk exposure to earthquake hazard for a given constructed facility. This can be expressed in terms of a Loss Ratio $\left(\mathrm{L}_{\mathrm{R}}\right)$ with respect to an earthquake ground motion that has an annual frequency, $\mathrm{P}_{\mathrm{a}}$. Using the total probability theorem, this relationship can be integrated to give the financial risk in terms of the expected annual loss.

5. For the typical highway bridge structure built to NZ codes and specifications that was examined herein, if located in a seismic zone where PGA $=0.4$ (such as Wellington), then the expected annualised loss due to earthquake damage is some $\$ 3,500$ per $\$ 1$ million of asset value. This is synonymous to an annual in perpetuity insurance policy to cover the expected losses.

6. Although the foregoing analysis sets forth a sound theoretical basis for examining the financial risk in terms of expected losses to constructed facilities, more work needs to be done before general application is made. First, a better description to the hazardrecurrence relations is needed. Results have shown that much of the expected damage arises from the more frequent but less severe events in the range of return periods from 10 to 100 years. If this were indeed true there would also be an empirical body of field evidence to support this prediction. An approach that assumes that earthquakes are a Poisson arrival process with a mean occurrence of say $v=50$ to 100 years (or even more in the case of the alpine fault) appears to be a promising place to start modifying the theory. Further sensitivity analyses to all principal parameters also need to be conducted.

\section{REFERENCES}

Carr A.J., 2004, "RUAUMOKO: Inelastic Dynamic Computer Program", Computer Program Library, Department of Civil Engineering, University of Canterbury, Christchurch, New Zealand.

Cornell C.A, Jalayer F., Hamburger R.O., and Foutch D.A., 2002, "Probabilistic Basis for 2000 SAC Federal Emergency Management Agency Steel Moment Frame Guidelines", ASCE Journal of Structural Engineering, April, pp 526-533.

Der Kiureghian A., 2005, "Non-ergodicity and PEER's framework formula", Earthquake Engineering and Structural Dynamics, 34 (13), pp 1643-1652.

Dhakal R.P., and Mander J.B., 2005, "Probabilistic Risk Assessment Methodology for Natural Hazards", Final Report submitted to Institute of Nuclear and Geological Sciences IGNS, Department of Civil Engineering, University of Canterbury, 60 pages.

Kennedy R.P., Cornell C.A., Campbell R.D., Kaplan S., and Perla H.F., 1980, "Probabilistic Seismic Safety Study of an Existing Nuclear Power Plant", Nuclear Engineering and Design No.59, pp 315-338

Lee K., and Foutch D.A., 2002, "Performance Evaluation of New Steel Frame Buildings for Seismic Loads", Earthquake Engineering and Structural Dynamics, 31 (3), pp 653-670.

Mander J.B., and Basoz N., 1999, "Enhancement of the Highway Transportation Lifeline Module in HAZUS", Federal Emergency Management Agency.

Martinez M.E., 2002, "Performance-Based Seismic Design and Probabilistic Assessment of Reinforced Concrete Moment Resisting Frame Structures", Master of Engineering Thesis, Department of Civil Engineering, University of Canterbury, New Zealand.

Standards New Zealand, 1995, "Concrete Structures Standards, Part I- The Design of Concrete Structures, NZS3101:1995".

Standards New Zealand, 1992, General Structural Design and Design Loadings for Buildings, NZS4203:1992.

Stirling M.W., McVerry G.H., and Berryman K.R., 2002, "A New Seismic Hazard Model for New Zealand", Bulletin of Seismological Society of America, Vol. 92, No. 5, pp 1878-1903.

Tanabe T., 1999, "Comparative Performance of Seismic Design codes for Concrete Structures", Vol. 1, Elsevier, New York.

Vamvatsikos D., and Cornell C.A., 2004, "Applied Incremental Dynamic Analysis", Earthquake Spectra, Vol.20 No.2, pp 523-553. 